\title{
IPSS Risk Score Greater than or Equal to 2.5
}

National Cancer Institute

\section{Source}

National Cancer Institute. IPSS Risk Score Greater than or Equal to 2.5. NCI Thesaurus.

Code C139300.

An International Prognostic Scoring System for Myelodysplastic Syndrome risk score greater than or equal to 2.5 , corresponding to high risk. 